\title{
O RISCO À DEMOCRACIA ANTE A MITIGAÇÃO DE DIREITOS FUNDAMENTAIS SOCIAIS COM A LEI 13.135/2015: A PERSPECTIVA DO "ESTADO EM CRISE" E APARENTE VIOLAÇÃO AO PRINCÍPIO DA PROIBIÇÃO DO RETROCESSO
}

\author{
THE RISK TO DEMOCRACY AGAINST THE MITIGATION OF SOCIAL \\ FUNDAMENTAL RIGHTS WITH LAW 13.135 / 2015: THE PERSPECTIVE OF THE \\ "STATE IN CRISIS" AND APPROPRIATE VIOLATION OF THE BANNING \\ PRINCIPLE OF THE BACKSPACE
}

\author{
${ }^{1}$ Karla Alexsandra Falcão Vieira Celestino \\ ${ }^{2}$ Daisy Rafaela da Silva
}

\section{RESUMO}

Este trabalho tem como objetivo analisar a ameaça à democracia, especialmente decorrente da perda de direitos sociais fundamentais, alcançados com uma riqueza de lutas e árduas conquistas, sob o frágil argumento de um Estado em crise, analisando a saída de um Estado social e garantidor para um Estado mínimo, e elaborando deste modo, um contrastante com o Princípio da Proibição do Retrocesso. Utilizou-se pesquisa bibliográfica e documental.

Palavras-chave: Direitos Sociais; Democracia; Proibição ao Retrocesso; Estado; Crise.

\begin{abstract}
This work aims at analyzing the threat to democracy, especially as a result of the loss of fundamental social rights, achieved with a wealth of struggles and arduous achievements, under the fragile argument of a state in crisis, analyzing the exit of a social state and guarantor for A minimum State, and thus elaborating a contrast with the Principle of Prohibition of Retraction. We used bibliographical and documentary research.
\end{abstract}

Keywords: Social rights; Democracy; Prohibition to Retreat; State; Crisis.

\footnotetext{
${ }^{1}$ Mestre em Direito pelo Centro Universitário Salesiano de São Paulo - UNISAL, (Brasil). Procuradora no Estado de Alagoas. E-mail: karlafalcao2013@yahoo.com.br

2 Doutora em Direito pelo Centro Universitário Salesiano de São Paulo - UNISAL, (Brasil).
}

Teorias do Direito e Realismo Jurídico | e-ISSN: 2525-9601 | Curitiba | v. 2 | n. 2 | p. 01 - 23 | Jul/Dez. 2016. 


\section{INTRODUÇÃO}

A Carta da República de 1988 é um marco democrático no Brasil, eis que, como uma significativa Carta de Direitos, reconheceu e garantiu os direitos fundamentais sociais básicos, instituindo a democracia e a observância sistemática e principiológica da dignidade da pessoa humana, almejando na atualidade não mais que a sua plena efetivação, pois, no dizer de Bobbio, mais relevante que o seu reconhecimento é a sua efetividade.

A Medida Provisória $n^{\circ}$ 664, publicada em 30.12.2014, e convertida na lei de $\mathrm{n}^{\mathrm{o}}$ 13.135 de 17 de Junho de 2015, alterou as regras da previdência social, sobretudo, mitigando direitos relacionados a pensão por morte e o auxílio doença, eis que, promoveu uma efetiva supressão de direitos fundamentais sociais conquistados a duras penas, sob o argumento falacioso de uma insofismável necessidade de corte nos gastos públicos.

Este trabalho tem como objetivo analisar a ameaça à democracia, especialmente decorrente da perda de direitos sociais fundamentais, alcançados com uma riqueza de lutas e árduas conquistas, sob o frágil argumento de um Estado em crise, analisando a saída de um Estado social e garantidor para um Estado mínimo, e elaborando deste modo, um contrastante com o Princípio da Proibição do Retrocesso.

O Estado quando pensado tinha por objetivo o de assegurar a proteção do indivíduo, o direito do Estado social fora sonhado e ordenado por tarefas de transformação social, de forma a promover a justiça, a democracia e a dignidade humana, realizando na pessoa, o objetivo central da sociedade e do Estado, o alfa e o ômega, garantido a esse mesmo indivíduo a proibição do retrocesso social, ou, no dizer de Canotilho, a contra evolução social, ou, a evolução reacionária.

E o que observamos na Lei 13.135/2015 é uma lei calcada na supressão de direitos dos trabalhadores conquistados ao longo dos anos, valendo-se de todo uma luta social que fora ignorada pelo Estado, sob a assertiva de medidas fundadas na redução de custos, sob o falacioso argumento de que a crise inevitavelmente suprime direitos. Ora, em decorrência da nova lei, a pensão por morte passou a ter prazo de validade, a pessoa beneficiária não é catalogada como pessoa, mas tipificada na sua idade, na quantidade de contribuições do falecido, de modo que, numa situação de perda, o Estado sem discutir com a sociedade, altera os benefícios a seu talante, com os olhos no patrimônio e não na pessoa. 
Deste modo, nota-se que o papel do Estado era o de assegurar o direito adquirido, o ato jurídico perfeito, no entanto, vemos de forma hodierna a prática de ações positivas tendentes a supostamente combater crise, comprometendo a democracia e extinguindo direitos sociais, os quais foram conquistados a duras penas, Destarte, sendo de suma relevância o papel do intérprete e aplicador enquanto realizador da norma, sobretudo no sentido de assegurar uma interpretação sistemática, principiológica, conforme a constituição, assegurando, precipuamente, a proibição do retrocesso.

Para abordar estes aspectos, o presente estudo, através do método da revisão bibliográfica, está subdividido em três. Primeiro, traz um breve histórico das dimensões dos direitos sociais, analisando a Lei 13.135/2015, sob a perspectiva da crise, analisando em seguida a origem da democracia e a ameaça decorrente da supressão de tais direitos fundamentais, e por fim as assertivas da doutrina a respeito do Princípio da proibição do retrocesso, conforme se pode conferir nos próximos itens.

\section{AS GERAÇÕES, E OU DIMENSÕES DOS DIREITOS FUNDAMENTAIS SOCIAIS}

Observamos que as gerações ou dimensões dos direitos fundamentais foram surgindo em vista dos acontecimentos e necessidades decorrentes da história, e Bobbio a respeito do surgimento dos direitos faz a seguinte assertiva:

\footnotetext{
(...) os direitos não nascem todos de uma vez. Nascem quando devem ou podem nascer. Nascem quando o aumento do poder do homem sobre o homem -que acompanha inevitavelmente o progresso técnico, isto é, o progresso da capacidade do homem de dominar a natureza e os outros homens ou cria novas ameaças à liberdade do indivíduo ou permite novos remédios para as suas indigências: ameaças que são enfrentadas através de demandas de limitação do poder; remédios que são providenciados através da exigência de que o mesmo poder intervenha de modo protetor. (1992, p. 31)
}

Cada novo ciclo de gerações de direitos, que vem a proteger as demandas sociais de uma fase histórica, não suprime e nem exclui as que o antecederam, ou seja, amoldam -se uns aos outros, conferindo eficácia máxima aos direitos fundamentais. A expressão dimensões de direitos é uma expressão moderna e atual, que corresponde a ideia de interatividade ou junção entre os direitos, não havendo encerramento em face de uma geração, mas, sim, uma relação interativa entre os direitos, tendo em vista que as necessidades do homem são constantes.

Teorias do Direito e Realismo Jurídico | e-ISSN: 2525-9601 | Curitiba | v. 2 | n. 2 | p. 01 - 23 | Jul/Dez. 2016. 
Destarte, há uma crítica da doutrina, especificamente de Sarlet, no tocante a expressão "geração", visto que poderia levar à equivocada conclusão de que uma nova etapa seria substitutiva e supressora do etapa anterior, quando, na verdade, são complementares (SARLET, 2010, p. 55)

No entanto, a despeito da discussão acerca da nomenclatura dos direitos humanos, Bobbio foi quem consagrou as gerações, ao afirmar que o "desenvolvimento dos direitos do homem passou por três fases", ou seja, inicialmente a referência as três primeiras gerações clássicas dos direitos fundamentais, liberdade, igualdade e fraternidade.

Neste trabalho, adota-se a expressão dimensões, apesar de a expressão gerações ser um tema didático do ponto de vista metodológico, uma vez que reporta a ideia de etapas evolutivas dos direitos humanos fundamentais, todavia, negativamente se sobrepõe o argumento de que a expressão "geração" tem como conotação a substituição de uma geração por outra, a ideia de que uma nova geração encerra a anterior, e que estes foram construídos em diferentes momentos históricos que não se entrelaçam entre si dificulta a aceitação acolhendo o entendimento de parte da doutrina que acolhe a terminologia de "gerações" por ser a mais apropriada. De acordo com Ingo Sarlet (2010), “[...] a teoria dimensional dos direitos fundamentais não aponta, tão-somente, para o caráter cumulativo do processo evolutivo e para a natureza complementar de todos os direitos fundamentais, mas afirma, para, além disso, sua unidade e indivisibilidade no contexto do direito constitucional interno [...]". Posteriormente, Sarlet faz uma defesa a respeito do termo dimensões, explicando a causa de sua opção por tal termo:

Em que pese o dissídio na esfera terminológica, verifica-se crescente convergência de opiniões no que concerne à idéia que norteia a concepção das três (ou quatro, se assim preferirmos) dimensões dos direitos fundamentais, no sentido de que estes, tendo tido sua trajetória existencial inaugurada com o reconhecimento formal nas primeiras Constituições escritas dos clássicos direitos de matriz liberal-burguesa, se encontram em constante processo de transformação, culminando com a recepção, nos catálogos constitucionais e na seara do Direito Internacional, de múltiplas e diferenciadas posições jurídicas, cujo conteúdo é tão variável quanto as transformações ocorridas na realidade social, política, cultural e econômica ao longo dos tempos. Assim sendo, a teoria dimensional dos direitos fundamentais não aponta, tão-somente, para o caráter cumulativo do processo evolutivo e para a natureza complementar de todos os direitos fundamentais, mas afirma, para além disso, sua unidade e indivisibilidade no contexto do direito constitucional interno e, de modo especial, na esfera do moderno 'Direito Internacional dos Direitos Humanos. (SARLET, 2010, p. 55)

Sobre o tema, Paulo Bonavides (1995, p. 35) aduz: 


\begin{abstract}
Os direitos da primeira geração são os direitos da liberdade, os primeiros a constarem do instrumento normativo constitucional, a saber, os direitos civis e políticos, que em grande parte correspondem, por um prisma histórico, àquela fase inaugural do constitucionalismo do Ocidente. Se hoje esses direitos parecem já pacíficos na condição política, em verdade se moveram em cada país constitucional num processo dinâmico e ascendente, entrecortado, não raro de eventuais recuos, conforme a natureza do respectivo modelo da sociedade, mas permitindo visualizar a cada passo uma trajetória que parte com frequência do mero reconhecimento formal para concretizações parciais e progressivas, até ganhar a máxima amplitude nos quadros consensuais de efetivação de democrática de poder.
\end{abstract}

E neste mesmo sentido aduz José Afonso da Silva:

(...)direitos fundamentais do homem-indivíduo, que são aqueles que reconhecem autonomia aos particulares, garantindo iniciativa e independência aos indivíduos diante dos demais membros da sociedade política e do próprio Estado; por isso são reconhecidos como direitos individuais, como é de tradição do Direito Constitucional brasileiro (art. $5^{\circ}$ ), e ainda por liberdades civis e liberdadesautonomia (França); (PIOVESAN, 2015, p.185)

Significa, portanto um verdadeiro direito de resistência, consubstanciado por um valor importante, que é a liberdade, segundo Bobbio (1992), "num primeiro momento, afirmaram-se os direitos de liberdade" os chamados direitos de primeira dimensão, em face sobretudo, de proteção das pessoas do poder opressivo do Estado, ou seja, eles aparecem na história juntamente com a Revolução Francesa, entre os séculos XVIII e XIX, como formar de afastar o pode absolutista da monarquia francesa.

Já a segunda dimensão de direitos fundamentais engloba todo o período das revoluções socialistas e nacionalistas, ou seja grande parte do século XIX e XX. As péssimas condições de trabalho e o apego excessivo ao modelo liberal-burguês impulsionaram o surgimento de uma nova demanda, que veio a ser atendida pelos direitos de segunda geração: os direitos sociais, culturais, econômicos e coletivos. A sua concretização exigia algo além do que a formalidade, vez que era necessária a concretude substancial da igualdade (SARLET, 2010, p. 47-48)

São os chamados direitos sociais, culturais e econômicos e surge com a queda do Estado Liberal e o nascimento do Estado do Bem-Estar Social, ou seja, o excesso de liberdade assegurado pelos direitos de primeira dimensão causou um desequilíbrio social que necessitava de reparação. Em virtude desse fato, afirmou Bobbio que esses tais "direitos políticos, os quais - conceberam a liberdade não apenas negativamente, como não impedimento, mas positivamente, como autonomia”. (p.32) 
Deste modo observamos que a segunda dimensão dos direitos fundamentais reclama do Estado uma ação que possa propiciar condições mínimas de vida digna, são os direitos sociais, econômicos e culturais, minimizando, portanto, as desigualdades sociais, e proporcionando, por conseguinte, proteção aos mais fracos.

Vale destacar que os direitos de segunda dimensão não negam, tampouco excluem os direitos de primeira dimensão, mas a estes se somam. E vejamos Celso Lafer:

A primeira geração de direitos viu-se igualmente complementada historicamente
pelo legado do socialismo, cabe dizer, pelas reivindicações dos desprivilegiados a
um direito de participar do "bem-estar social", entendido como os bens que os
homens, através de um processo coletivo, vão acumulando no tempo. É por essa
razão que os assim chamados direitos de segunda geração, previstos pelo welfare
state, são direitos de crédito do indivíduo em relação à coletividade. Tais direitos -
como o direito ao trabalho, à saúde, à educação - têm como sujeito passivo o Estado
porque, na interação entre governantes e governados, foi a coletividade que assumiu
a responsabilidade de atendê-los. O titular desse direito, no entanto, continua sendo
como nos direitos de primeira geração, o homem na sua individualidade. Daí a
complementaridade, na perspectiva ex parte populi, entre os direitos de primeira e
segunda geração, pois estes últimos buscam assegurar as condições para o pleno
exercício dos primeiros, eliminando ou atenuando os impedimentos ao pleno uso das
capacidades humanas". (PIOVESAN, 2015, p.127)

Assim sendo a segunda geração, os denominados direitos de igualdade (ou liberdade positiva), impõem uma ação estatal, um facere, consubstanciada nos direitos econômicos, sociais e culturais. Tais direitos visam propiciar os mecanismos necessários para à efetivação dos direitos individuais. Se o Estado se omite, acaba por caracterizar a violação do direito.

E destaca Bonavides (1999, p. 29):

Os direitos de segunda geração merecem um exame mais amplo. Dominam o século
XX do mesmo modo como os direitos de primeira geração dominaram o século
passado.São os direitos sociais, culturais e econômicos bem como os direitos
coletivos ou de coletividades, introduzidos no constitucionalismo das distintas
formas de Estado Social, depois que germinaram por obra da ideologia e da reflexão
antiliberal do século XX. Nasceram abraçados ao princípio da igualdade, do qual
não se podem separar, pois fazê-lo equivaleria a desmembrá-los da razão de ser que
os ampara e estimula.

Deste modo, com os direitos da segunda dimensão, nasceu, outrossim, um pensamento de que, tão relevante quanto valorizar e preservar o indivíduo, segundo a definição clássica de liberdade, era também despertar a conscientização de proteger a instituição, uma realidade social mais fecunda à participação e valoração da pessoa humana.

É oportuno dizer que as mudanças do final do século XX, a massificação das relações de consumo, a questão ambiental e o desenvolvimento tecnológico-científico incrementaram um conteúdo complexo e até então distinto nessa nova sociedade. A consciência de um 
mundo partido entre nações desenvolvidas e subdesenvolvidas, deu razão a que se buscasse uma outra dimensão dos direitos fundamentais, a modificação da visão do ser humano em si, ou de determinada coletividade para a relação dele com o contexto coletivo, com o meio ambiente de forma solidária e fraterna.

A terceira dimensão, portanto, emerge com o término da $2^{\mathrm{a}}$ guerra mundial e da criação da ONU, reunindo, destarte os chamados direitos de solidariedade, os direitos do povo numa perspectiva difusa, os quais exigem dos cidadãos uma participação intensa na efetivação destes direitos fundamentais. E destaca Bonavides (1999, p. 569):

Com efeito, um novo pólo jurídico de alforria do homem se acrescenta historicamente aos da liberdade e da igualdade. Dotados de altíssimo teor de humanismo e universalidade, os direitos da terceira geração tendem a cristalizar-se no fim de século XX enquanto direitos que não se destinam especificamente à proteção dos interesses de um indivíduo, de um grupo ou de um determinado Estado. Têm primeiro por destinatário o gênero humano mesmo, num momento expressivo de sua afirmação como valor supremo em termos de existencialidade concreta. Os publicistas e juristas já o enumeram com familiaridade, assinalando-lhe o caráter fascinante de coroamento de uma evolução de trezentos anos na esteira da concretização dos direitos fundamentais. Emergiram eles da reflexão sobre temas referentes ao desenvolvimento, à paz, ao meio ambiente, à comunicação e ao patrimônio comum da humanidade.

Paulo Bonavides afirma acerca dos direitos de terceira dimensão, citando Mbaya, (1999, p.570):

\footnotetext{
Admite que a descoberta e a formulação de novos direitos são e sempre serão um processo sem fim, de tal modo que quando "um sistema de direitos se faz conhecido e reconhecido, abrem-se novas regiões da liberdade que devem ser exploradas". Com base nessa constatação, proclama o jurista a adequação e a propriedade de linguagem relativa ao reconhecimento de três gerações de direitos fundados no princípio da solidariedade.(...) "1. O dever de todo estado particular de levar em conta, nos seus atos, os interesses de outros estados (ou de seus súditos); "2. Ajuda recíproca(bilateral ou multilateral), de caráter financeiro ou de outra natureza, para a superação das dificuldades econômicas (inclusive com auxílio técnico aos países subdesenvolvidos e estabelecimento de preferências de comércio em favor desses países, a fim de liquidar déficits); e 3. Uma coordenação sistemática de política econômica.
}

Os direitos de terceira dimensão sintetizam os direitos da primeira e da segunda dimensão, sob o viés da solidariedade, valorizando o ser humano na sua complexidade a fim de que sejam iguais em dignidade, em liberdade, em igualdade, tendo como cerne o homem na sua integralidade, sem fragmentos, sem divisões, e em real relacionamento com outros povos. 
No que concerne aos direitos de quarta dimensão, na atualidade há doutrinadores que defendem a existência destes direitos, apesar de ainda não haver consenso na doutrina sobre qual o conteúdo dessa espécie de direito. Para Bobbio (1992, p.40), :(...) "tratam-se dos direitos relacionados à engenharia genética." Isso porque o mundo assiste ao avanço implacável das pesquisas no campo da engenharia genética, às profundas alterações na política mundial, proporcionadas, sobretudo, pela globalização econômica, ou seja, preocupase então na instituição de mecanismos jurídicos tendentes à preservação da própria existência do homem na Terra.

Bonavides (1999) sustenta a existência dos direitos de quarta geração, com aspecto introduzido pela globalização política, relacionados à democracia, à informação, ao pluralismo e a globalização dos direitos fundamentais e afirma: "Daqui se pode, assim, partir para asserção de que os direitos da segunda, da terceira e da quarta gerações, não se interpretam, concretizam-se. É na esteira dessa concretização que reside o futuro da globalização política, o seu princípio de legitimidade, a força incorporadora de seus valores de libertação." E segue o autor:

\begin{abstract}
A globalização política neoliberal caminha silenciosa, sem nenhuma referência de valores. (...) Há, contudo, outra globalização política, que ora se desenvolve, sobre a qual não tem jurisdição a ideologia neoliberal. Radica-se na teoria dos direitos fundamentais. A única verdadeiramente que interessa aos povos da periferia. Globalizar direitos fundamentais equivale a universalizá-los no campo institucional. (...) A globalização política na esfera da normatividade jurídica introduz os direitos de quarta geração, que, aliás, correspondem à derradeira fase de institucionalização do Estado social. São direitos de quarta geração o direito à democracia, o direito à informação e o direito ao pluralismo. Deles depende a concretização da sociedade aberta do futuro, em sua dimensão de máxima universalidade, para a qual parece o mundo inclinar-se no plano de todas as relações de convivência. (...) Ao contrário, os direitos da primeira geração, direitos individuais, os da segunda, direitos sociais, e os da terceira, direitos ao desenvolvimento, ao meio ambiente, à paz e à fraternidade, permanecem eficazes, são infra-estruturais, formam a pirâmide cujo ápice é o direito à democracia; coroamento daquela globalização política para a qual, como no provérbio chinês da grande muralha,a Humanidade parece caminhar a todo vapor, depois de ter dado seu primeiro e largo passo.(BONAVIDES, 1999, p.571572)
\end{abstract}

Além de Paulo Bonavides, outros constitucionalistas vêm promovendo o reconhecimento dos direitos de quarta dimensão, conforme podemos perceber nas palavras do Marcelo Novelino (2008, p. 229), quando ressalta que: “(...)tais direitos foram introduzidos no âmbito jurídico pela globalização política, compreendem o direito à democracia, informação e pluralismo. Os direitos fundamentais de quarta dimensão compendiam o futuro da cidadania e 
correspondem à derradeira fase da institucionalização do Estado social sendo imprescindíveis para a realização e legitimidade da globalização política.” (NOVELINO, 2008, p.229)

E ainda Pietro de Jésus:

O passo dos direitos fundamentais a essa nova dimensão de reconhecimento de direitos se deve a que, se já há algum tempo é perfeitamente possível observar a manipulação de animais e vegetais, hoje a manipulação é sobre o ser humano diretamente, colocando-se no mundo uma discussão inicial sobre as possibilidades de se dispor do patrimônio genético individual, evitando a manipulação sobre os genes e ao mesmo tempo, mantendo-se a garantia de gozar das contemporâneas técnicas de engenharia genética. (ALARCÓN, 2004, p. 90.)

Importante trazer a tona parte do julgamento de trinta e seis paginas do ministro Gilmar Mendes, analisando as pesquisas com células-tronco embrionárias, e que por intermédio da ética é possível avaliar o agir humano com responsabilidade, averiguando seus limites e os impactos das novas tecnologias, segue parte do julgado:

Trago a tona as lições de Hans Jonas para afirmar que o Estado deve atuar segundo o princípio da responsabilidade, As novas tecnologias ensejaram uma mudança radical na capacidade do homem de transformar seu próprio mundo e, nessa perspectiva, por em risco sua própria existência. E o homem tornou-se objeto da própria técnica. Como assevera Hans Jonas, o homo faber aplica sua arte sobre si mesmo e se habilita a refabricar inventivamente o inventor e o confeccionador de todo o resto. $\mathrm{O}$ homo faber ergue-se diante do homo sapiens. A manipulação genética, um sonho ambicioso do homo faber de controlar sua própria evolução, demonstra a necessidade de uma nova ética do agir humano, uma ética de responsabilidade ensina Hans Jones - contrapõe a tarefa mais modesta que obriga ao temor e ao respeito: conservar que nenhuma mudança das circunstâncias poderá suprimir seu mundo e sua essência contra os abusos de seu poder. (STF, 2016)

O acontecimento do malogrado dia do 11 de setembro nos EUA, o crescimento progressivo do ódio entre as culturas e a religião, a disputa crescente entre nações e a nova movimentação bélica pós-atentados terroristas guiaram o constitucionalista Bonavides (2011, p. 590) a uma reflexão sobre a necessidade de uma quinta dimensão de direitos fundamentais: "o direito à paz, enquanto direitos de quinta geração". E segue o autor:

Estuário de aspirações coletivas de muitos séculos, a paz é o corolário de todas as justificações em que a razão humana sob o pálio da lei e da justiça, fundamenta o ato de reger a sociedade, de modo a punir o terrorista, julgar o criminoso de guerra, encarcerar o torturador, manter invioláveis as bases do pacto social, estabelecer e conservar, por intangíveis, as regras, os princípios e cláusulas de comunhão política. $\mathrm{O}$ direito à paz é o direito natural dos povos. Direito que esteve em estado de natureza no contratualismo socialde Rosseau ou que ficou implícito como um dogma na paz perpétua de Kant.(p.590) 
Imprescindível destacar que a apresentação acima detalhada das dimensões dos direitos fundamentais trata-se de um método acadêmico, uma vez que os direitos dos seres humanos são relacionados, complementares, associados entre si, retratando apenas a definição e a preponderância na valorização de determinados direitos em momentos históricos distintos, Com efeito, os direitos humanos são um construído, um sim e um ainda não, e no dizer de Hannah Arendt, os direitos humanos como construção da igualdade, e que o primeiro direito humano é o direito a ter direitos.(LAFER, 2006, p.154) .

\section{A CRISE NA PERSPECTIVA DA LEI 13.135/2015}

A crise é uma palavra hodiernamente trazida na mídia, nas discussões filosóficas, sociais, e no dia a dia do cidadão do mundo, que nos remota a dificuldade financeira, a falta de liquidez, e, na atualidade comumente utilizada pelo Estado para justificar a eliminação dos direitos fundamentais sociais, sob o argumento falacioso de que todos devem sacrificar direitos em virtude da malograda crise.

Interessante a assertiva de Carlos Bordoni, em sua obra Estado de Crise, com Zygmunt Bauman, quando afirma:

Qualquer acontecimento adverso, em especial os concernentes ao setor econômico,é "culpa da crise". Trata-se de uma atribuição de responsabilidade absolutamente despersonalizada, a qual liberta indivíduos de todo e qualquer envolvimento e faz alusão a uma entidade abstrata, o que soa vagamente sinistro. Isso acontece porque algum tempo atrás a palavra crise perdeu seu significado original e assumiu uma conotação apenas econômica. Ela substituiu outras palavras que foram historicamente desvirtuadas, como "conjuntura", usada com frequência nos anos1960 e 1970, quando a situação econômica geral era mais otimista, abrindo caminho a temporadas nas quais o consumismo de massa reinou impertubardo.(BORDONI; BAUMAN, 2016, p.10)

E segue o autor:

Uma conjuntura era um período curto em comparação com todo o restante. (...) já implicava uma atitude positiva, confiante em relação ao futuro imediato, em contraste com outros termos comumente usados para designar dificuldades econômicas, no passado. (...) Contudo, a crise atual é diferente. Os países afetados pela crise estão endividados demais e não têm vigor, talvez nem sequer os instrumentos, para investir. Tudo o que podem fazer são cortes aleatórios, os quais têm o efeito de exacerbar a recessão, em vez de mitigar seu impacto sobre os cidadãos."(IDEM)

Vale notar que a crise ameaça a própria democracia, uma vez que direitos que foram conquistados por meio de conquistas sociais estão ameaçados pelo discurso neo liberal, com o argumento de um Estado mínimo, e tal assertiva se constata através da Lei 13.135/2015, em

Teorias do Direito e Realismo Jurídico | e-ISSN: 2525-9601 | Curitiba | v. 2 | n. 2 | p. 01 - 23 | Jul/Dez. 2016 
que pese a mitigação de direitos sociais associados a previdência, os quais foram subtraídos de seus titulares, sem sequer uma discussão racional, não permitindo que os atores sociais participassem da discussão, ou seja, a referida Lei era na verdade a Medida Provisória 664/2014 convertida em lei.

Ora, em um discurso racional inexiste a necessidade de aprovação de medidas de mitigação de direitos sociais no apagar das luzes, por meio de uma MP, onde não há nem urgência nem relevância, demonstrando que o objetivo do Estado era a subtração dos direitos sociais a seu talante, comprometendo a democracia e o estado de direito.

Segundo Ezio Mauro, em sua Obra BABEL, com Zygmunt Bauman, a crise invade a democracia de uma forma tão agressiva ameaçando no dizer do autor, "tudo o que criamos para desenvolver e aperfeiçoar o mecanismo de democracia" e segue:

Como um exército invasor num reino adormecido, a crise marcha com facilidade desconcertante por sobre a totalidade do sistema material, institucional e intelectual das estruturas democráticas que o Ocidente erigiu depois da guerra: governos, parlamentos, órgãos intermediários, sujeitos sociais, antagonismos, o Estado de bem-estar social, partidos e movimentos nacionais, internacionais e continentais vale dizer, tudo o que criamos para desenvolver e aperfeiçoar o mecanismo de democracia, tendo em vista nos proteger nas nossas vidas em conjunto. (...) Nós agora sabemos que esse mecanismo não é capaz de nos proteger. (...) A democracia E continua o autor: não é auto suficiente. (BAUMAN, MAURO, 2016, p.11)

(...) autonomia da crise. A crise é indiferente ao processo democrático, ela atua sob sua linha de sombra projetada, por assim dizer, tirando vantagem das fraquezas desse processo e exagerando-as. (...) trata-se de uma força que afirma sua autonomia sem qualquer teoria perceptível de si mesma e de sua ação, sem projeto, mas com uma força de ação cujas conseqüências são dolorosamente visíveis;(IDEM ,p.13, 2016)

Ora, segundo Bonavides, os direitos fundamentais sociais são o oxigênio das constituições democráticas, no entanto, a preocupação atual diz respeito em como efetivar tais direitos, na medida em que estamos avançando na conquista de alguns direitos básicos, todavia, ameaçados, em que pese a iminência de retrocesso dos mesmos, em face da atuação positiva do Estado, que a seu talante e sob o argumento da crise, suprime direitos que já fazem parte da pessoa humana no âmbito da coletividade.

O Estado tem o dever de respeito e proteção aos direitos fundamentais, contudo, na concepção de um Estado mínimo a crise exerce uma dimensão exagerada, aproveitando-se para mitigar os direitos sociais com o falacioso argumento da crise, e afirma Ezio Mauro (2016, p. 13): 
(...) Como a democracia está sob ataque - pois esta é a questão em jogo hoje -, nós devemos indagar se ela ainda é capaz de pensar sobre si mesma, se ainda é capaz de se repensar, de modo a imaginar de novo e recuperar o poder de governar de fato.

E como se trata a presente obra de um diálogo de Ezio Mauro e Zygmunt Bauman, este faz uma a seguinte declaração:

(...) a presente crise, que afeta todos os aspectos da nossa condição, atinge profundamente "tudo o que criamos para desenvolver e aperfeiçoar o mecanismo da democracia, tendo em vista nos proteger nas nossas vidas em conjunto." E cita Thomas Paine em um documento Senso Comum de 1776: "quando sofremos, ou somos expostos por um governo às mesmas misérias que poderíamos esperar de um país sem governo, nossa calamidade é ampliada pela reflexão de que nós mesmos suprimos os meios pelos quais sofremos". E ainda por Thomas Hobbes ter proclamado em seu Leviatã e afirma: "outro documento fundador da modernidade que a garantia e o provimento de segurança são a razão primordial, a tarefa suprema e a obrigação inegável do Estado, portanto, sua raison d'etre.” (...) O propósito de ter governo é estar seguro. (...) Contudo, como esses dois valores não são na prática plenamente conciliáveis (para qualquer aumento da segurança é preciso pagar uma parte de liberdade, e vice-versa)." Conforme nos previu Paine, hoje nós estamos "expostos por um governo às mesmas misérias que esperaríamos de um país sem governo. (2016, p.14)

Necessário constar que a crise nos afeta e nos torna vulneráveis de tal modo, que nos dá uma sensação de medo, enfraquecendo, destarte, a estrutura social que nos envolve, e o papel do Estado que seria o de proteger e dá segurança, é ao contrário, no dizer de Ezio, "os principais suspeitos ante a nova insegurança que se expande", há uma quebra da confiança que compromete a democracia. E continua o autor:

(...) pelo livre desempenho da política, nós havíamos construído um meio comum de legitimar o poder político jurídico e os papeis que dele derivam (...) se esse mecanismo cessa, o Estado cede à crise, as finanças se transformam em variável independente, o trabalho vira mercadoria instável, em vez de meio para estabelecer relação com os outros, a globalização distorce proporcionalmente a arena da crise e, enfim, o papel do cidadão e dos laços de dependência recíproca que ligam os indivíduos ao poder público acaba desmoronando também.(2016, p. 18)

E ainda:

Ele esclarece citando então Jacques Julliard: "quando o sistema de representação se torna "mau condutor da vontade geral" num nível mais profundo, a "rejeição da política revela a aspiração cega de autonomia do indivíduo, uma espécie de alergia à própria noção de governo". E segue Ezio Mauro(...) “a alergia ao governo que o cidadão que o cidadão decepcionado está sofrendo confunde e questiona os conceitos fundamentais da filosofia política moderna; ela se espalha dos governos e partidos para o Estado e suas Instituições, até chegar ao seu estágio final, ao qual nós já chegamos: uma alergia a própria democracia. (...)Eis o novo par da pósdemocracia - o Estado e o cidadão -, forçado a conviver sem nenhuma razão para isso, pois toda a paixão de um pelo outro se extinguiu." (2016, p.18) 
Ora, o que se verifica é que a edição da Lei 13.135/2015 representou uma efetiva restrição de direitos fundamentais sociais de previdência social, eis que estabeleceu requisitos que não se constituem legítimos, como por exemplo a carência de 18 meses de contribuição para os beneficiários de pensão por morte, a extinção da vitaliciedade desse benefício para os cônjuges e companheiros, mediante a aplicação de uma tabela de expectativa de vida, a qual é revista ademais a cada três anos, outrossim, condicionando a cônjuges e a companheiros o mínimo de 2 (dois) anos de casamento ou união estável, senão vejamos as malsinadas modificações:

Art. 77. ............................................................

II - para filho, pessoa a ele equiparada ou irmão, de ambos os sexos, ao completar 21 (vinte e um) anos de idade, salvo se for inválido ou com deficiência;

III - para filho ou irmão inválido, pela cessação da invalidez;

IV - para filho ou irmão que tenha deficiência intelectual ou mental ou deficiência grave, pelo afastamento da deficiência, nos termos do regulamento; (Vigência)

$\mathrm{V}$ - para cônjuge ou companheiro:

a) se inválido ou com deficiência, pela cessação da invalidez ou pelo afastamento da deficiência, respeitados os períodos mínimos decorrentes da aplicação das alíneas "b" e "c";

b) em 4 (quatro) meses, se o óbito ocorrer sem que o segurado tenha vertido 18 (dezoito) contribuições mensais ou se o casamento ou a união estável tiverem sido iniciados em menos de 2 (dois) anos antes do óbito do segurado;

c) transcorridos os seguintes períodos, estabelecidos de acordo com a idade do beneficiário na data de óbito do segurado, se o óbito ocorrer depois de vertidas 18 (dezoito) contribuições mensais e pelo menos 2 (dois) anos após o início do casamento ou da união estável:

1) 3 (três) anos, com menos de 21 (vinte e um) anos de idade;

2) 6 (seis) anos, entre 21 (vinte e um) e 26 (vinte e seis) anos de idade;

3) 10 (dez) anos, entre 27 (vinte e sete) e 29 (vinte e nove) anos de idade;

4) 15 (quinze) anos, entre 30 (trinta) e 40 (quarenta) anos de idade;

5) 20 (vinte) anos, entre 41 (quarenta e um) e 43 (quarenta e três) anos de idade;

6) vitalícia, com 44 (quarenta e quatro) ou mais anos de idade.

Ora, não é de difícil percepção que os dispositivos acima descritos representam o comprometimento da dignidade humana, a mitigação de direitos sociais alcançados a um elevado custo à sociedade, pois, a pensão por morte, antes vitalícia agora tem suas limitações próprias e sem qualquer justificativa razoável, o cônjuge ou companheiro que não tiver dois anos de casamento ou união estável somente terá direito a 4(quatro) meses de contribuição, e passado esse período estão entregues a própria sorte, violando, portanto, tais disposições a segurança jurídica, a dignidade humana e a própria democracia. 
Canotilho, em sua obra Direito Constitucional e Teoria da Constituição, aduz que a função de defesa ou de liberdade dos direitos fundamentais tem dupla dimensão: "(1) constituem, num plano jurídico-objectivo, normas de competência negativa para os poderes públicos, proibindo fundamentalmente as ingerências destes na esfera jurídica individual; (2) implica, num plano jurídico-subjectivo, o poder de exercer positivamente direitos fundamentais (liberdade positiva) e de exigir omissões dos poderes públicos, de forma a evitar agressões lesivas por parte dos mesmos (liberdade negativa)" (CANOTILHO, 2002, p. 407).

Esse dever de abstenção-respeito, faz despontar a necessidade de medidas procedimentais e organizacionais por parte do Estado, obstando lesões aos direitos de um trabalho digno, minimizando a perda de direitos conquistados a duras penas, emanando do poder público a tarefa inconteste de edificar uma ordem jurídica que assegure o direito adquirido, viabilizando a observância do princípio da dignidade da pessoa humana.

O princípio do Estado de Direito ordena tarefas ao Estado, sendo estas de transformação social, de forma a promover a justiça social, a democracia, a dignidade humana, realizando na pessoa, o objetivo central da sociedade e do estado, o alfa e o ômega, garantido a esse mesmo indivíduo a proibição do retrocesso social, ou, no dizer de Canotilho, a contra evolução social, ou, a evolução reacionária.

"O direito como instrumento de conformação social". Constitui como objetivo do Estado de direito democrático, através do art. $2^{\circ}$ da Constituição portuguesa, a realização da democracia econômica, social e cultural, ou seja, uma forma de garantia da efetivação destes direitos. E no dizer de Canotilho:

O princípio da democracia económica e social constitui uma autorização constitucional no sentido de o legislador democrático e os outros órgãos encarregados da concretização político-constitucional adaptarem as medidas necessárias para a evolução da ordem constitucional sob a ótica de uma justiça constitucional nos vestes de uma justiça social. (2003, p.338)

E ainda:

\begin{abstract}
O princípio da democracia económica, social e cultural tem a mesma dignidade constitucional do princípio do estado de direito e do princípio da democracia política, estando, tal como eles, garantindo contra leis de revisão especialmente pervesoras. Todavia, ele apresenta duas dimensões especificas relativamente a estes dois princípios: (1) uma dimensão teleológica, pois a democracia económica, social e cultural é um objetivo a realizar no contexto de um processo público aberto "Estado social como processo" - e, por isso ela apresenta-se como um fim do Estado (art.9.$l d)$; (2) uma dimensão impositivo - constitucional, pois muitas de suas concretizações assentam no cumprimento de fins e tarefas por parte de órgãos e entidades públicas. (2003, p.337)
\end{abstract}




\title{
E continua o mestre:
}

\begin{abstract}
No seu cerne essencial, o princípio da democracia económica, social e cultural é um mandato constitucional juridicamente vinculativo que limita a discricionariedade legislativa quanto ao (se) da actuação, deixando, porém, uma margem considerável de liberdade de conformação política quanto ao como da sua concretização (cfr. Ac TC 189/80).
\end{abstract}

A proteção dos direitos fundamentais sociais se dá em face do legislador, do poder executivo, de maneira que conquistas reconhecidas em âmbito constitucional, atreladas a dignidade humana, a uma vida digna, não podem ser subtraídas ao alvitre de quem quer que seja, pois, passam a fazer parte da esfera jurídica individual, e, com bastante propriedade aduz Canotilho:

\begin{abstract}
O princípio da democracia económica e social aponta para a proibição de retrocesso social. A idéia aqui expressa também tem sido designada como proibição de contrarevolução social ou da evolução reaccionária. Com isto quer dizer-se que os direitos sociais e económicos (ex.: direito dos trabalhadores, direito à assistência, direito a educação), uma vez obtido um determinado grau de realização, passam a constituir, simultaneamente, uma garantia institucional e um direito subjetivo. A "proibição do retrocesso social" nada pode fazer contra as recessões e crises económicas (reversibilidade fáctica), mas o princípio em análise limita a reversibilidade dos direitos adquiridos (ex.: segurança social, subsídio de desemprego, prestações de saúde, em clara violação do princípio de protecção da confiança e da segurança dos cidadãos no âmbito económico, social e cultural, e do núcleo essencial da existência mínima inerente ao respeito pela dignidade da pessoa humana.(2003, p.339)
\end{abstract}

E da forma como analisamos a malsinada lei, constatamos que os art.77 e suas disposições, em momento algum levaram em conta a pessoa, os direitos a ela associados, mas como um meio para o alcance de metas de redução de custos, ainda que tal atitude caracterize violação de direito fundamental social, e traga a tona o princípio da proibição do retrocesso, eis que,não se trata exclusivamente de medidas retroativas, mas da atuação positiva do Estado em retirar direitos já consolidados, até que ponto o executivo pode atuar negativamente em direitos já conquistados.

E em meio a este pensamento Canotilho aduz em seguida:

O princípio da democracia económica e social é um elemento essencial de interpretação na forma de interpretação conforme a constituição. O legislador, a administração e os tribunais terão de considerar o princípio da democracia económica e social como princípio obrigatório de interpretação para avaliar a conformidade dos actos do poder público com a constituição. (2003, p.341) 
Neste sentido vê-se que o Estado necessita exercitar a sua legitimidade, reafirmar a aceitação de suas condutas, ou seja, as suas ações precisam corresponder a efetiva proteção social, elas precisam corresponder ao "dever-abstenção" citado por Canotilho, retomando a condição de garantidor de segurança, tratando o indivíduo como fim em si mesmo e não meio, sob pena de ameaça à própria democracia. Bauman (2016) sugere como medicina preventiva para salvar a democracia contra o abandono, a vulnerabilidade e as demais doenças sociais correlatas a condição da nossa forma de analisar, (...)“ da nossa capacidade e da nossa resolução de olhar, pensar e agir acima das fronteiras dos Estados Territoriais.

E Ezio Mauro com muita precisão mantendo o diálogo com Bauman acrescenta:

\begin{abstract}
Nós vivemos num período de interregno, portanto, e isso pode ajudar a explicar a crise de governança, de autoridade, de representação. Estamos suspensos entre o "não existe mais" e o "não existe ainda", e por isso somos necessariamente instáveis - nada à nossa volta é fixo, nem sequer a direção da nossa viagem. E segue o autor: "Não confiamos nas instituições que criamos para nós mesmos, em última análise, duvidamos da própria democracia, que parecia a única religião que nos restava alguns pensavam que ela estava destinada a ser universal - depois da queda dos falsos deuses que criamos no século XX.(...) quando a política não é capaz de ter peso em nossa vida cotidiana, quando não responde às nossas preocupações sobre $\mathrm{o}$ futuro dos nossos filhos, para que precisamos dela, qual o valor do seu uso? O destino da democracia segundo Ezio, "parece estar nessa ruptura de pacto entre Estado e o cidadão (2016, p.25)
\end{abstract}

O que se observa é a manifesta mitigação de direitos fundamentais sociais, na medida em que por meio de uma medida provisória, posteriormente convertida em lei, o indivíduo perdera direitos, e, como se não bastasse a dificuldade em alcançá-los, inobstante, todo um contexto social envolvido, a sociedade assiste a efetiva supressão dos mesmos e a consequente violação do Princípio da Proibição do Retrocesso.

\title{
3. A PROIBIÇÃO DO RETROCESSO E A DEMOCRACIA EM CRISE
}

Todas as vezes que se reporta a democracia, a proibição do retrocesso e a crise, incontestável se apresenta a afirmação de que o Estado está passando por uma profunda crise de identidade, afastando-se da sua razão fundadora, o homem em si mesmo, esquecendo-se que seu propósito fundamental não é organizar e equilibrar o orçamento, mas proteger o cidadão, assegurar a proteção desse núcleo essencial citado por Bonavides, senão vejamos: 


\begin{abstract}
A violação do núcleo essencial efectivado justificará a sanção de inconstitucionalidade relativamente a normas manifestamente aniquiladoras da chamada justiça social.... O princípio da proibição do retrocesso social pode formular-se assim: o núcleo essencial dos direitos sociais já realizado e efectivado através de medidas legislativas ("lei da segurança social", "lei do subsídio de desemprego", "lei do serviço de saúde") deve considerar constitucionalmente garantido, sendo inconstitucionais quaisquer medidas estaduais que, sem a criação de outros esquemas alternativos ou compensatórios, se traduzam, na prática, numa "anulação, "revogação", ou "aniquilação" pura e simples desse núcleo essencial. Não se trata, pois, de proibir um retrocesso social captado em termos gerais ou de garantir em abstrato um status quo social, mas de proteger direitos fundamentais sociais, sobretudo, no seu núcleo essencial.(CANOTILHO, 2003, p.340)
\end{abstract}

Note-se que tais direitos fundamentais sociais foram conquistados numa perspectiva histórica e sociológica, ou seja, os mesmos possuem uma conjuntura histórica de Constituição, e de modo refratário o Estado se opõe negativamente, subtraindo-os de sua esfera jurídica, tornando-os de uma hora para outra desprovidos destes direitos, demonstrando, sobretudo, indiferença à realidade de seus administrados, ou seja, quem deveria guardar e proteger, se lança a execução de medidas abortivas aos direitos sociais.

E no dizer de Sarlet, os direitos fundamentais sociais são direitos conquistados a duras penas, correspondem a direitos às prestações e direitos de defesa, senão vejamos:

\begin{abstract}
...demonstrando que os direitos sociais, pelo menos no constitucionalismo pátrio, compõe um complexo amplo e multifacetado de posições jurídicas, de tal sorte que a denominação de direitos sociais encontra sua razão de ser "na circunstância - comum aos direitos sociais prestacionais e direitos sociais de defesa - de que todos consideram o ser humano na sua situação concreta na ordem comunitária (social), objetivando, em princípio, a criação e garantia de uma igualdade e liberdade material (real), seja por meio de determinadas prestações materiais e normativas, seja pela proteção e manutenção do equilíbrio de forças na esfera das relações trabalhista. (SARLET, 2016).
\end{abstract}

Ao Estado incumbe a proteção destes direitos fundamentais sociais, eis que se relacionam ao mínimo existencial, tendo como parâmetro a dignidade da pessoa humana, eis que, tão importante quanto salvaguardar o direito individual, é proteger os direitos conquistados no âmbito social, pois, quando alcançamos o todo, alcançamos a parte, no pensamento complexo de Edgar Morin.

\title{
E continua Sarlet:
}

Com efeito, a dignidade não será suficientemente respeitada e protegida em todo o lugar onde as pessoas estejam sendo atingidas por tal nível de estabilidade jurídica que não estejam mais em condições de, com um mínimo de segurança e tranquilidade, confiar nas instituições sociais e estatais (incluindo o Direito) e numa certa estabilidade das suas próprias posições

Teorias do Direito e Realismo Jurídico | e-ISSN: 2525-9601 | Curitiba | v. 2 | n. 2 | p. 01 - 23 | Jul/Dez. 2016. 
jurídicas. Dito de outro modo, a plena e descontrolada disponibilização dos direitos e dos projetos de vida pessoais por parte da ordem jurídica acabaria por transformar os mesmos (e, portanto, os seus titulares e autores) em simples instrumento da vontade estatal, sendo, portanto, manifestamente incompatível mesmo com uma visão estritamente kantiniana da dignidade.(SARLET, 2010, p. 451)

\section{Com precisão Sarlet esclarece:}

Assim, convém relembrar que, havendo (ou não) menção expressa no âmbito do direito positivo a um direito à segurança jurídica, de há muito, pelo menos no âmbito do pensamento constitucional contemporâneo, se enraizou a idéia de que um autêntico Estado de Direito é sempre também - pelo menos em princípio e num certo sentido - um Estado da segurança jurídica, já que, do contrário, também "o governo das leis" (até pelo fato de serem expressão da vontade política de um grupo) poderá resultar em despotismo e toda a sorte de iniquidades. Com efeito, a doutrina constitucional contemporânea tem considerado a segurança jurídica como expressão inarredável do Estado de Direito, de tal sorte que a segurança jurídica passou a ter o status de subprincípio concretizador do princípio fundamental e estruturante do Estado de Direito. (SARLET, 2010, p. 451)

Deste modo, o princípio da segurança jurídica assegura as partes o direito a uma situação estável e concreta, e a Proibição do retrocesso está intimamente ligada ao referido princípio, uma vez que, garante aos envolvidos na relação jurídica, o direito a não ter a sua esfera jurídica alterada ao sabor do legislativo, do executivo e em inobservância aos direitos fundamentais sociais.

E esta lei, nos diversos artigos que a compõe, retrata a concreção do retrocesso aos direitos alcançados, vemos que com o subterfúgio de organizar as contas públicas, de forma reiterada o indivíduo assiste a remoção de direitos que já fazem parte da sua dignidade, e o Estado, não obstante, o seu pode do príncipe, tem que se limitar a uma atuação não prejudicial a sociedade, atuando até o limite de não afetação dos direitos fundamentais sociais alcançados ao longo dos anos.

\section{E destaca Sarlet:}

Por outro lado, há como sustentar que, na base dos direitos sociais aqui versados e expressamente consagrados pelo nosso Constituinte, se encontra a necessidade de preservar a própria vida humana, não apenas na condição de mera sobrevivência física do indivíduo (aspecto que assume especial relevância no caso de direito a saúde), mas também de uma sobrevivência que atenda aos mais elementares padrões de dignidade. (IDEM)

A referida lei traz a tona o fato do poder público objetivar de forma hodierna a resolução administrativa e financeira, por meio da malograda supressão de direitos fundamentais sociais, fraudando, frustrando e inviabilizando políticas públicas próprias, sob a 
alegação da reserva do possível, quando tal conduta negativa ameaça, ou, efetivamente, aniquila tais direitos sociais impregnados de essencial fundamentalidade.

De fato observamos que há limitação de recurso, todavia, o Estado não pode beneficiar-se da sua própria torpeza, devendo ter uma atuação de modo a priorizar a pessoa humana, a efetivação de políticas públicas que promovam e assegurem a dignidade humana, destarte, na referida lei assistimos inertes o avanço na perda de direitos sociais, a limitação na concessão de pensão por morte, a valorização excessiva do custo orçamentário da previdência, em detrimento do bem estar da pessoa, do beneficiário de tal direito, julgando, destarte, a prevalência do bem sobre a pessoa, o que contraria a meta central da nossa Carta Maior, que é o bem estar social.

Neste sentido constatamos que o poder público tem o papel de garantir aos seus administrados a segurança na prática de seus atos, não podendo atuar de modo arbitrário e indiferente as necessidades efetivas de seu povo, de maneira que o indivíduo deve ter a segurança institucional, o respeito a observância de sua dignidade. E o que fazer, quando o estado ao seu talante promulga lei que lhe subtrai a sua pensão por morte caso você tenha menos de 2(dois) anos de casado.

Luís Roberto Barroso, citando Kant, aduz:

\begin{abstract}
A dignidade da pessoa humana é a idéia que informa, na filosofia, o imperativo categórico kantiano, dando a origem a proposições éticas superadoras do utilitarismo: a) uma pessoa deve agir como se a máxima de sua conduta pudesse transformar-se em uma lei universal; b) cada indivíduo deve ser tratado como um fim em si mesmo, e não como um meio para a realização de metas coletivas ou de outras metas individuais. As coisas tem preço; as pessoas tem dignidade. (2014, p. 41)
\end{abstract}

Com efeito, para Ingo Sarlet, a questão central que se coloca neste contexto específico da proibição do retrocesso é a de saber se e até que ponto pode o legislador infraconstitucional (assim como os demais órgãos estatais, quando for o caso) voltar atrás no que diz com a implementação dos direitos fundamentais sociais, assim como dos objetivos estabelecidos pelo constituinte em seu art. $3^{\circ}$.

O reconhecimentos da proteção destes direitos sociais, subjetivamente adquiridos, conquistados democraticamente, representa um limite jurídico do legislador, de modo que, as alterações realizadas devam ocorrer sem que haja a perda ou violação de qualquer elemento desse núcleo essencial de direitos sociais já alcançados, sem que haja um compensação de tais 
perdas, não podendo assim serem retiradas da ordem social posta, sem que se caracterize violação dos mesmos e ameaça a própria democracia. E segundo Ezio Mauro:

(...) depois de ter derrotado as ditaduras, a democracia não se instala no controle para sempre. Ela deve lutar por supremacia diariamente, num esforço constante para provar sua própria legitimidade." E o autor na sua descrição sobre esse "interregno" ele assevera: “(...) "o interregno é também um período em que a irracionalidade da decadência germina sem restrição, numa rebelião mais motivada por angustia que por liberdade verdadeira, um período que surgem figuras xamânicas que reduzem o mecanismo político ao seu carisma, fazem apelos aos nossos instintos, emocionalmente, e engendram medos para transormá-los em grandes trivialidades, como se fosse possível soluções simples para problemas complexos." E segue o autor citando a advertência de Nietzsche, senão vejamos: "Nietzsche nos advertiu de que, em períodos de decadência, é fácil perder "a capacidade espontânea de se autoregular coletiva e individualmente", de tal modo que "preferimos o artificial ao real", deixando prevalecer os "motivos desinteressados" a ponto de escolhermos (instintivamente) o que é pernicioso.” (MAURO; BAUMAN, 2016, p.26)

E ainda citando a compreensão de Bobbio:

(...) explicou dizendo que a política foi inventada para nos permitir dedicar tempo a desatar os nós do mundo contemporâneo, enquanto o populismo propõe cortar esses nós com uma espada . (...)logo vai querer se livrar das restrições de controles e de procedimento, logo vai começar a vê-las como uma teia que restringe o poder dos eleitos e limita o esplendor da liderança. (...) a espada que destrói procedimentos e regras, como se eles não fossem o sistema de garantias que criamos para nós mesmos ao conviver. (1992, p.29)

Não se trata, portanto, da proibição simplesmente ideológica de um retrocesso social, mas de assegurar a revogação de direitos já consolidados no âmbito social, questiona-se, destarte, a legitimidade do Estado em revogar direitos fundamentais sociais, contrariando, pois, o núcleo essencial da CF de 1988, eis que, na condição de um estado democrático e de direito, inadmissível infirmar tais direitos em inobservância a dignidade da pessoa humana.

No que concerne a reserva do possível pode ser chamada também de "reserva do financeiramente possível" ou ainda "reserva da consistência", onde o Estado de forma habitual, tenta se esquivar de prestações fundamentais sociais, sob a alegação da reserva do possível, no entanto, o que observamos por diversas vezes é a falta de vontade e planejamento do Estado na efetivação dos direitos sociais, além da inobservância com o princípio da dignidade humana. 


\section{CONCLUSÃO}

Destarte, observamos que os direitos fundamentais sociais, ainda que mínimos, quando são muitos, de fato provocam um certo efeito financeiro, todavia, a força do princípio da competência orçamentária não é ilimitada, eis que, os direitos individuais podem ter peso maior que razões orçamentárias e políticas.

Diante do exposto, evidencia-se que os dispositivos constantes nas modificações decorrentes da Lei 13.135/2015, representam uma ameaça a efetivação dos direitos fundamentais sociais, retrata uma verdadeira mitigação destes direitos, além de risco incipiente à democracia, uma vez que o Estado perde legitimidade, sobretudo, quando não cumpre seu papel de proteção, de abstenção, de garantidor.

Em que pese, sob o argumento falacioso de recessão e crise econômica, vemos o Estado infirmar direitos conquistados a duras penas, em absoluta inobservância à ordem constitucional contemporânea, não levando em conta que tais direitos, que tal garantia institucional, está atrelada a dignidade do indivíduo, e que a supressão dos mesmos configura uma lesão direta ao estado democrático de direito.

\section{REFERÊNCIAS}

ALARCÓN, Pietro de Jésus Lora. O patrimônio genético humano e sua proteção na Constituição Federal de 1988. São Paulo: Método, 2004.

BARCEllos, Ana Paula de. A Eficácia Jurídica dos Princípios Constitucionais. O Princípio da Dignidade da Pessoa Humana, Rio de Janeiro: 2002.

\section{BARROSO, Luis Roberto. A dignidade da Pessoa Humana no Direito}

Constitucional Contemporâneo: a construção de um conceito jurídico à luz da Jurisprudência Mundial, Ed. Forum. 2012. 
BARROSO, Luis Roberto. Curso de Direito Constitucional Contemporâneo: Os conceitos Fundamentais e a Construção do novo modelo. São Paulo: Saraiva, 2014.

O Direito Constitucional e a Efetividade das Normas. Rio de Janeiro: Renovar, 2009.

BAUMAN, Zygmunt; MAURO, Ezio. BABEL: entre a incerteza e a esperança. Rio de Janeiro: Zahar, 2016.

BAUMAN, Zygmunt; BORDONI, Carlo. Estado de Crise. Rio de Janeiro: Zahar, 2016.

BOBBIO, Norberto. A Era dos Direitos. Trad. Carlos Nelson Coutinho. Rio de Janeiro: Campus, 1992.

BONAVIDES, Paulo. Curso de Direito Constitucional. São Paulo: Malheiros, 1999.

CANOTILHIO, José Joaquim Gomes. Direito Constitucional e Teoria da Constituição. São Paulo: Almedina, 2003.

LAFER, Celso. A reconstrução dos direitos humanos: um diálogo com o pensamento de Hannah Arendt. 6. ed. São Paulo: Companhia das Letras, 2006.

NOVELINO, Marcelo. Direito Constitucional. 2.ed. Rev. Atual. e ampl. São Paulo: Método, 2008.

PIOVESAN, Flávia. Direitos Humanos e Justiça Internacional. São Paulo: Saraiva, 2015.

SARLET, Ingo Wolfgang. A eficácia dos Direitos Fundamentais. Uma Teoria Geral dos Direitos Fundamentais na perspectiva constitucional. 12 ${ }^{\mathrm{a}}$ Ed. revisada, atualizada e ampliada. Porto Alegre, 2015.

Teorias do Direito e Realismo Jurídico | e-ISSN: 2525-9601 | Curitiba | v. 2 | n. 2 | p. 01 - 23 | Jul/Dez. 2016 
SARLET, Ingo Wolfgang. A Eficácia dos Direitos Fundamentais. $8^{\text {a }}$ Edição, Porto Alegre: Livraria do Advogado, 2010.

SARLET, Ingo Wolfgang. Os direitos fundamentais sociais na Constituição de 1988. Disponível em: $<$ http://www.direitopublico.com.br/pdf_seguro/REVISTA-DIALOGOJURIDICO-01-2001-INGO-SARLET.pdf>. Acesso em 12 de setembro de 2016.

SILVA, Virgílio Afonso da (Org.). Interpretação constitucional. São Paulo: Malheiros, 2005.

SILVA, Virgílio Afonso da. Direitos fundamentais: conteúdo essencial, restrições e eficácia. 2. ed. São Paulo: Malheiros, 2010.

SUPREMO TRIBUNAL FEDERAL. Disponível em:<http://www.stf.jus.br/arquivo/cms/noticiaNoticiaStf/anexo/ADI3510GM.pdf>. A cesso em 22.08.2016 